\title{
Mitral surgery on the precipice of transformation
}

\author{
Lawrence M. Wei, MD, Harold G. Roberts, MD, and Vinay Badhwar, MD
}

\author{
From the Department of Cardiovascular and Thoracic Surgery, West Virginia University, Morgantown, WVa. \\ Disclosures: Authors have nothing to disclose with regard to commercial support. \\ Received for publication Oct 31, 2017; accepted for publication Nov 9, 2017; available ahead of print Dec 6, 2017 \\ Address for reprints: Vinay Badhwar, MD, Department of Cardiovascular \& Thoracic Surgery, West Virginia Uni- \\ versity, 1 Medical Center Drive, Morgantown, WV 26506-8059 (E-mail: vinay.badhwar@wvumedicine.org). \\ J Thorac Cardiovasc Surg 2018;155:945-6 \\ $0022-5223 / \$ 36.00$ \\ Copyright (C) 2017 by The American Association for Thoracic Surgery \\ https://doi.org/10.1016/j.jtcvs.2017.11.011
}

In the current issue of the Journal, Dearani ${ }^{1}$ provides a thoughtful reflection on the growing national experience with robotic mitral valve operations, as evidenced by the first 1000 case experiences of Gillinov and colleagues. ${ }^{2}$ When a standardized approach to patients selected for robotic mitral surgery was used, in-hospital outcomes at the Cleveland Clinic revealed a high repair rate and low early mortality for focal degenerative disease. As Dearani ${ }^{1}$ astutely points out, high-volume centers with experienced mitral repair surgeons being highly selective in which cases are performed robotically is a clear recipe for success. However, is this recipe applicable to all surgeons and all centers? Does this prescriptive approach help propel the field forward? Yes and no.

Gillinov and colleagues ${ }^{2}$ are to be commended for a large series and outstanding results. Although other reports ${ }^{3-5}$ have also documented the safety and efficacy of robotically assisted mitral valve surgery, their algorithmderived selectiveness to include patients without reduced ejection fraction, moderate-severe pulmonary hypertension, mitral calcification or image-guided peripheral vascular disease offers a bona fide pathway to launch a safe and successful program. However, once center and surgeon expertise can be attained, reproducibility of excellent outcomes may actually provide a natural impetus for a broader application to those patients at greater risk who stand to benefit most from the aggregate advantages a robotic approach.

Much has been learned during the 25-year evolution of minimally invasive and robotic mitral surgery. Advances in perfusion and robotic technology have now made these operations reproducible and routine in many centers. ${ }^{6}$ Early concerns with myocardial protection and peripheral malperfusion have given way to consistent outcome improvements to align with, and perhaps even surpass, those achieved with sternotomy. ${ }^{3-6}$ Currently, $14 \%$ of all mitral operations in the United States are performed via a minimally invasive right thoracotomy, and $11 \%$ of all mitral repairs are performed robotically. ${ }^{7,8}$ Although a substantive advance over years past, clearly many more patients could potentially benefit

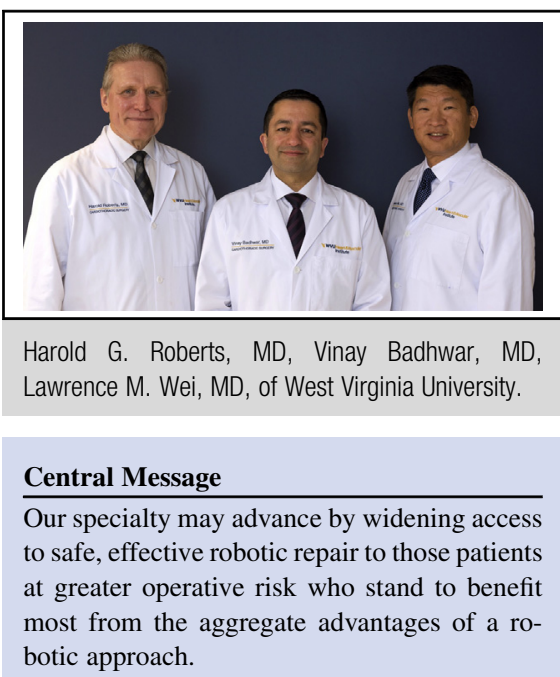

See Article page 943.

from the rapid recovery to normal activity afforded by a minimally invasive approach.

It is resolved that to be a safe and effective robotic mitral valve surgeon/center, one must first have reasonable mastery of open mitral repair, consistent volume, the support of an excellent intraoperative team, and access to high-quality echocardiography and computed tomography angiography. ${ }^{9}$ Preoperative transesophageal imaging is essential to provide pathoanatomic-directed mitral planning at all levels of experience. However, following stepwise progression and a track record of safety with minimally invasive video-assisted operations, many experienced robotic programs now effectively approach nearly all mitral patients robotically. This includes all pathologies counting endocarditis and patients deemed to be at greater risk for sternotomy. Virtually all isolated mitral and/or tricuspid operations, concomitant surgical ablation for atrial fibrillation, or stand-alone surgical ablation may be approached robotically. Techniques identical to those used in sternotomy cases are employed, including rigid partial and complete annuloplasty rings, sliding leaflet valvuloplasty, neochordae, autologous pericardial patches, and mitral valve replacement for stenosis.

Yet, before a widespread shift to robotic technology can be expected, telemanipulation must show superiority over conventional video-assisted mitral repair on the basis of durability at advancing levels of pathoanatomic complexity. If established, then training and dissemination of the cumulative experience must be shared to make this a routine, and perhaps cost-effective procedure in all advanced mitral 
centers. For the evolving mitral specialist, mastery of safe and durable robotic mitral repair is an essential companion to one's simultaneous expertise in transcatheter mitral repair and replacement.

In the journal Science, Kaebnick and colleagues ${ }^{10}$ recently described that the optimal approach to emerging technology is to balance precaution with meaningful scientific advancement. For robotic mitral surgery, we must not reject precautionists out of hand as obstructing innovation. Precaution must serve as the meaningful guardrails to a broader advancement of our specialty. Given recent advances in the safe, effective, and reproducible outcomes achieved with robotic telemanipulation, if we can respect the epistemologic guardrails of precaution as we advance to all levels of complexity, we will soon arrive at the precipice of a transformation of mitral surgery in which the high-quality, routine approach to repair will be provided robotically.

\section{References}

1. Dearani JA. Robotic heart surgery: hype or hope? J Thorac Cardiovasc Surg. 2018;155:943-4.
2. Gillinov AM, Mihaljevic T, Javadikasgari H, Suri RM, Mick SL, Navia JL, et al. Early results of robotically assisted mitral valve surgery: analysis of the first 1000 cases. J Thorac Cardiovasc Surg. 2018;155:82-91.

3. Murphy DA, Moss E, Binongo J, Miller JS, Macheers SK, Sarin EL, et al. The expanding role of endoscopic robotics in mitral valve surgery: 1,257 consecutive procedures. Ann Thorac Surg. 2015;100:1675-81.

4. Ramzy D, Trento A, Cheng W, De Robertis MA, Mirocha J, Ruzza A, et al. Three hundred robotic-assisted mitral valve repairs: the Cedars-Sinai experience. $J$ Thorac Cardiovasc Surg. 2014;147:228-35.

5. Suri RM, Burkhart HM, Daly RC, Dearani JA, Park SJ, Sundt TM III, et al. Robotic mitral valve repair for all prolapse subsets using techniques identical to open valvuloplasty: establishing the benchmark against which percutaneous interventions should be judged. J Thorac Cardiovasc Surg. 2011;142:970-9.

6. Badhwar V. Are we going backwards or forwards in minimally invasive mitral valve surgery? Three eras of perfusion strategy. Semin Thorac Cardiovasc Surg. 2015;27:104-5.

7. Badhwar V, Rankin JS, He X, Jacobs JP, Gammie JS, Furnary AP, et al. The Society of Thoracic Surgeons mitral repair/replacement composite score: a report of The Society of Thoracic Surgeons Quality Measurement Task Force. Ann Thorac Surg. 2016;101:2265-71.

8. D'Agostino RS, Jacobs JP, Badhwar V, Paone G, Rankin JS, Han JM, et al. The Society of Thoracic Surgeons adult cardiac surgery database: 2017 update on outcomes and quality. Ann Thorac Surg. 2017;103:18-24.

9. Rodriguez E, Nifong LW, Bonatti J, Casula R, Falk V, Folliguet TA, et al. Pathway for surgeons and programs to establish and maintain a successful robot-assisted adult cardiac surgery program. J Thorac Cardiovasc Surg. 2016; 152:9-13.

10. Kaebnick GE, Heitman E, Collins JP, Delborne JA, Landis WG, Sawyer K, et al. Precaution and governance of emerging technologies. Science. 2016;354:710-1. 